Meta

Journal des traducteurs

Translators' Journal

\title{
Globalization and the Politics of Translation Studies
}

\section{Anthony Pym}

Volume 51, numéro 4, décembre 2006

La traduction des noms propres (1) et Langue, traduction et mondialisation : interactions d'hier, interactions d'aujourd'hui Language, Translation and Globalization: Interactions from Yesterday, Interactions from Today (2)

URI : https://id.erudit.org/iderudit/014339ar

DOI : https://doi.org/10.7202/014339ar

Aller au sommaire du numéro

\section{Éditeur(s)}

Les Presses de l'Université de Montréal

ISSN

0026-0452 (imprimé)

1492-1421 (numérique)

Découvrir la revue

Citer cet article

Pym, A. (2006). Globalization and the Politics of Translation Studies. Meta, 51(4), 744-757. https://doi.org/10.7202/014339ar

\section{Résumé de l'article}

Vue comme résultat de l'application des technologies réduisant les coûts reliés aux communications, la mondialisation favorise à la fois le recours massif à l'anglais, lingua franca, et l'accroissement de la demande des traductions. Ce paradoxe apparent s'explique par la dichotomie entre les stratégies de production, d'une part, et les modes de diffusion des informations, d'autre part. Or, c'est la diffusion, et elle seulement, qui donne son caractère pérenne à la traduction. La nouveauté essentielle de la mondialisation est parfaitement illustrée dans la localisation multiple à partir d'un matériau internationalisé (géométrie de l'« un-à-plusieurs "), là où autrefois on travaillait suivant le modèle une source-une cible, encore le plus étudié par la traductologie. La discipline qui étudie la traduction s'organise pourtant autour d'un ensemble de principes politiques qui, tout en restant fidèles au binarisme source-cible, pourraient redéfinir la traductologie dans le contexte mondialisant. Parmi ces principes, relevons l'organisation des formations encadrée par des plans nationaux ou régionaux, la défense des cultures minoritaires, et l'investissement dans l'altérité culturelle. La pertinence même de ces principes est examinée dans les pages qui suivent à la lumière de trois états de fait : le manque relatif de recherches américaines sur la traduction, l'organisation d'une association internationale des traductologues, et le rejet des boycottages nationalistes à l'endroit des chercheurs.
Ce document est protégé par la loi sur le droit d'auteur. L'utilisation des services d'Érudit (y compris la reproduction) est assujettie à sa politique d'utilisation que vous pouvez consulter en ligne.

https://apropos.erudit.org/fr/usagers/politique-dutilisation/ 


\title{
Globalization and the Politics of Translation Studies
}

\author{
ANTHONY PYM \\ Universitat Rovira $i$ Virgili, Tarragona, Spain \\ anthony.pym@urv.cat
}

\begin{abstract}
RÉSUMÉ
Vue comme résultat de l'application des technologies réduisant les coûts reliés aux communications, la mondialisation favorise à la fois le recours massif à l'anglais, lingua franca, et l'accroissement de la demande des traductions. Ce paradoxe apparent s'explique par la dichotomie entre les stratégies de production, d'une part, et les modes de diffusion des informations, d'autre part. Or, c'est la diffusion, et elle seulement, qui donne son caractère pérenne à la traduction. La nouveauté essentielle de la mondialisation est parfaitement illustrée dans la localisation multiple à partir d'un matériau internationalisé (géométrie de l'«un-à-plusieurs»), là où autrefois on travaillait suivant le modèle une source-une cible, encore le plus étudié par la traductologie. La discipline qui étudie la traduction s'organise pourtant autour d'un ensemble de principes politiques qui, tout en restant fidèles au binarisme source-cible, pourraient redéfinir la traductologie dans le contexte mondialisant. Parmi ces principes, relevons l'organisation des formations encadrée par des plans nationaux ou régionaux, la défense des cultures minoritaires, et l'investissement dans l'altérité culturelle. La pertinence même de ces principes est examinée dans les pages qui suivent à la lumière de trois états de fait: le manque relatif de recherches américaines sur la traduction, l'organisation d'une association internationale des traductologues, et le rejet des boycottages nationalistes à l'endroit des chercheurs.
\end{abstract}

\begin{abstract}
Globalization can be seen as a consequence of technologies reducing the costs of communication. This reduction has led both to the rise of English as the international lingua franca and to an increase in the global demand for translations. The simultaneous movement on both fronts is explained by the divergent communication strategies informing the production and distribution of information, where translation can only be expected to remain significant for distribution, and not for production. The fundamental change in the resulting communication patterns is the emergence of one-to-many document production processes, which are displacing the traditional source-target models still used in Translation Studies. Translation Studies might nevertheless retain a set of political principles that could constitute its own identity with respect to globalization. Such principles would be expressed in the national and regional organization of the discipline, in the defense of minority cultures, and in a general stake in cultural alterity. The possible existence of such principles is here examined on the basis of three instances where Translation Studies might address globalization in political terms: the weakness of the discipline in dominant monocultures, the development of an international association of Translation Studies, and political boycotts of translation scholars.
\end{abstract}

\section{MOTS-CLÉS/KEYWORDS}

globalization, politics, technologies, translation studies

Here we shall attempt to model globalization as an economic process that has certain consequences for the social role of translation. Those consequences will then be seen 
as affecting the political organization of Translation Studies as a scholarly discipline. The general economic process is held to have certain elements of irreversibility thanks to its grounding in technological change. Translators will mostly have to come to terms with those elements, as will scholars and everyone else. There are, however, properly political processes that build on globalization but should not be identified with it. Those processes also have consequences for translation, but they are not to be considered inevitable. Some of them can be resisted or influenced by the use or nonuse of translation. Those political processes can be indirectly affected by a scholarly Translation Studies, which might thus develop its own politics with respect to globalization. This means that Translation Studies should seek to understand and explain the effects of globalization, without pretending to resist them all. At the same time, it should attempt to influence the more negative political processes within its reach, developing political agendas and cultivating its own political organization. In this, the dialectics play out between the technological and the political, between the things we must live with and the things we should try to change. Only with this double vision should we attempt to take a position with respect to globalization.

\section{The Technological}

Globalization, for our present purposes, results from a progressive reduction in the costs of communication and transport. The term can mean many other things as well; the current theories cover everything from the state of markets to the condition of the soul. But for us, here, globalization will be no more than a set of things that can happen when distance becomes easier to conquer. Let us model those things. Let us try to connect them with translation and its study.

Here is one model. As technology improves, we can move things further and more efficiently, just as we can potentially communicate more efficiently and over greater stretches of time and space. What is reduced on both these levels might be called the transaction costs, understood as the total effort necessary just to get the objects moved or the communication under way. Different technologies structure these costs in different ways. Sometimes apparently slight changes can have large-scale effects. The technological move from parchment to paper, for example, cheapened rewriting processes, enabling translations with multiple revisions, greater teamwork and wider distribution. Not by chance, the arrival of paper coincided with the significant translation activities in Baghdad in the ninth and tenth centuries, and with those in Hispania in the twelfth and thirteenth (see Pym 2000a). Similarly, the printing press enabled much wider distribution, at the same time as it required the fixing of a definitive text. This led to spelling conventions and the standardization of national languages, while the ideally definitive text promoted greater awareness of individualist discourse (the style of the author), with corresponding calls for individualist translators. The age of print was also that of national languages and the individual translator, as well as the ideal of equivalence (since there was a technologically fixed text to which a rendition could be equivalent). And what now of our electronic means of communication? They are mostly cheaper still, allowing transaction costs to be structured in quite different ways. Revision practices are no longer an addition to translation; they have become essential to text production (websites are constantly updated) and for translation as an extension of that process. The kind of equivalence 
promoted by the printing press is no longer pertinent when the source texts are constantly evolving by electronic means. Underlying those conceptual ruptures, however, the general reduction of transaction costs has been going on for centuries.

What consequences might that extended process have for the way translation interacts with globalization, up to and including our electronic age? With cursory glances at recent history, a certain chain of reasoning can be linked as follows:

- As transport and communication become cheaper, more things are moved and communicated over greater distances. This hypothesis is in accordance with the assumed benefits of trade and the unhappy supposition that people tend to do everything that technology makes it possible for them to do. As precarious as the hypothesis might be in human terms, the statistics for global transport and communications do indicate an accelerating rise.

- There is thus more communication. This is not only because it is easier to communicate but also because there are more moving things about which to communicate, more possible communication partners to talk with, more possibilities for communication about the resulting communication, and indeed more technology to talk about in the first place. Did we ever imagine, prior to email and mobile phones, that so much needed to be said?

- The quantitative rise in communication is first within the borders of cultures and languages (since there is less resistance from cultural and linguistic differences), then progressively across those borders.

- When communication regularly crosses the borders of languages and cultures, it tends to wash away those same borders. Thus were the local patois and fiefdoms swamped by the vernaculars and nation states. Thus, also, are the nation states and their languages transformed into parts of greater regions. And so, too, have the regions formed into intercontinental markets with a growing lingua franca. The end of that process would be communication on a truly planetary scale. Prior to that point, however, globalization is not global; it is a convenient misnomer for an incomplete development.

- Globalization thus creates the need for common languages, therefore the need for fewer languages, and now the need for just one lingua franca, English.

- As the borders are washed away, so too is the need for translation. We will soon all speak English all the time, so the whole translation profession is doomed to extinction. Translation Studies will lose its object, and we might as well face up to the fact. Such are the consequences of technology.

There is a lot wrong with that model, and not just because its conclusion is sad. The model can be used to reduce globalization to cultural homogenization, to McDonalds and Coca Cola and Microsoft ruling the world, as is done often enough. Globalization quickly becomes a process to be resisted, as if there were an enemy somewhere constantly pulling the strings, as if there were always causal connections being manipulated, as if we faced a for-or-against situation of some kind, as if there were no technology at the base of change. In need of opposition, some would occasionally try to read the model in reverse, courageously hoping the evils of globalization can be countered by politically promoting languages, by increasing the number of translations, or simply by translating differently (cf. the "call to action" in Venuti 1995). The tide advances, Canute retreats; so if Canute advances, the tide will retreat? Here are a handful of reasons why those simple cause-and-effect models fail:

- Despite the tragic decline in the number of the world's living languages, the number of translations would so far seem to have increased with similar drama. Yes, increased. Boucau (2005: 9), working from a wide range of business sources, states that the global 
translation market has grown rapidly in the past 20 years and puts the current growth rate at between 5 and $7.5 \%$ per year. A longer constant increase can be found in the Index Translationum since 1932 (under the auspices of UNESCO since 1948, computerized since 1979). All the numbers indicate a constant rise in the numbers of translations carried out in the world; we are aware of no numbers that intimate a fall. This rise would be alongside (not opposed to) the growth of international English. Globalization would seem to promote both the lingua franca and the demand for translations. If we cannot explain this apparent paradox, then perhaps we are not grasping globalization. Our acts of political resistance are likely to be well meant, well reasoned, politically correct, and poorly aimed.

- The real and tragic decline in the number and diversity of the world's living languages probably has more to do with urbanization. The same technologies that restructure transaction costs also bring people in from plains and down from mountains, in a way that is not easily reversible by means of mere communication.

- Globalization, in our technological sense, mostly affects the discourses where the technology for cross-cultural transport and communication is actually used. Many parts of our lives are not subject to it in any radical way; our loves, hates and dreams often proceed virtually untouched, as do local and national politics, for example. Globalization is by no means the only narrative in town. As Brian Mossop correctly pointed out at the Halifax conference, state-financed translations across Canada's official bilingualism are affected by technology and transaction costs, yet they by no means conform to general models of globalization. Other histories are also working themselves out. Globalization is not global, nor need it be.

- Those discourses that are affected quite probably change much more than the simple quantities would suggest. The production of technology and global services moves the very places from which discourses are initiated and elaborated. And that, above all, is what we have to try to understand and explain.

These objections should produce a slightly more complex view. Globalization is neither the friend nor the foe of translation. It is quite simply changing many of the situations in which translation is called upon to operate. And it is doing so on a technological level that involves elements of irreversibility. Translation scholars should be able to grasp and respond to that process.

How is it that the numbers of translations might increase at the same time as English triumphs and many languages are forced into twilight? This is what I have elsewhere termed the "diversity paradox". By rights, growing use of the lingua franca should be reducing cultural diversity, whereas the use of translation should be maintaining the same diversity. So how can the two processes occur at the same time? How exactly could globalization lead both to an international lingua franca and to a rise in the market for translations?

The answer to this must lie in the increasing differences between the economic categories of production and distribution.

The effect of globalization on production can broadly be seen as an extension of Ricardan trade, creating centers of international specialization. Portugal was (and still is) good at producing wine; Britain was better (at that time) at manufacturing cloth, so it was theoretically preferable for each to specialize and for systematic trade to result. Globalization, promoting quantitative increase in international trade, should allow further specialization of this kind, and thus greater regional diversity. Any neoclassical economist will tell you that international trade promotes specialization in production, not global homogeneity. There is much evidence in support of that view. 
We tend not to complain about globalization when our port comes from Porto, our scotch from Scotland, our films from Hollywood or Bollywood or Cairo, our suits from Italy, our software programs from the west coast of the United States, or indeed our software localization from Ireland. Regional specialization is not hard to find; it would be much harder to argue that globalization allows everything to be produced everywhere.

This diversity-through-trade argument should probably help us explain why translation is still very necessary. Products have to be moved from the specialized places in which they are produced; their information thus has to cross linguistic and cultural borders; documents have to be translated.

Much as Ricardan economics was good for the early nineteenth century, it requires adaptation before it can say much about our own situation. Let us suggest three modifications:

- The main point to add is quite obvious. The regional diversity gained on the level of trade is progressively lost on the level of distribution. One consequence of specialized production is greater homogeneity in consumption. Economists tend to privilege production (as indeed do linguists); cultural critics are usually more worried about the globalization of distribution. The main point is that the regional configurations of the two levels are now remarkably different. How does this concern translation? For a start, the cultural distances between the points of production and consumption have been stretched to extremes, requiring enormous amounts of communication, some of which is translational.

- The second point should also be easy enough. Few of the classical theories envisaged the places of production and consumption as being anything other than nation states or regions, where internal cultural diversity would not disturb the boxes where the statistics sat. That is no longer the case. Production is usually specialized on a scale smaller than the nation state (except for small states like the Caribbean island of Grenada, which is the world's second largest exporter of nutmeg). We tend to talk about a productive focus defined by local geographies or, in the case of technological production, the human and financial resources networked in cities. Production is eminently local, often surprisingly so. It develops centers of specialization in the very face of political calls for decentralization, and despite the technological possibilities for a more international networking of the relations of production. In the age of globalization, production is certainly not global in any homogenizing sense. People still need to see each other from time to time, to inhabit the same air, to partake of a localized production culture. What does this have to do with translation? Well, for instance, why is it that the translators working exclusively through the Internet struggle to find clients and must fight to keep them? Why do translators themselves form companies and cooperatives where they can meet with each other face to face? Indeed, in the age of electronic communication, why do we have the largest centralized translation bureau in the world, in Brussels-Luxembourg (admittedly split in two, in shameless lip-service to decentralization, and with a wide dispersed fringe of freelancers). Such nodes tend to be located near the centers of production (in the case of Brussels let us allow that political decisions are produced). In all of this, the human values of contact have much to say, particularly in view of the key role played by trust in the translator's interpersonal relations. Yet there is still more.

- Perhaps the main modification to be made to Ricardan diversity-through-trade is that language and communication technologies must now be seen as integral parts of the means of production. When the wine had to flow to Britain and the cloth had to unfold in Portugal, some kind of English-Portuguese translation was theoretically needed for the contact situation. The language interface was a minor transaction cost that had to 
be covered by the benefits of trade. However, once we are actually producing language and communication (as does the Brussels eurocracy, for example), language and communication technologies start to configure the very places of production. Such places need not correspond to the presumed primacy of nation states, regions, or anything other than the relations of production themselves. For Ricardan economics, port wine is produced in Portugal because that is where they do it for the least expenditure of labor. On the other hand, much computer programming tends to be done in technical varieties of English because that is the language most adapted to the task, no matter where the actual production is carried out. In the latter case, which is the kind of globalization most in tune with an electronic age, language and communication help form the place of production. People become increasingly able to participate in relations of production independently of the cultures and languages that they previously had, and independently of the culture and language operative in the country where they work. The move from the first model (language and communication as additional trade costs) to the second (language and communication as forming relations of production) may be of little importance in many fields. Yet it assumes radical proportions in the domains of production most affected by technology, particularly communications technology. After all, those are the fields where the decrease in transaction costs has most impact.

The important point about the revised model, the one where language and communication actually enter the relations of production, is that the configuration of production can be radically different from the tendency to homogenization operative on the level of distribution.

Only that revised model can really explain the prolonged vitality of translation. Only that model can see languages as playing one role in production and quite another in distribution. To put it in a reductive nutshell, the lingua franca plays its global role as a factor of production, whereas translation plays its marketing role as a tool of distribution. On this view, translation into the languages of production should be fundamentally different, in general, from translation from those languages. And that asymmetry is so basic and so powerful that little resistance seems called for.

To tell the same story again:

Let us suppose that the economies of globalization centralize production in the fields most affected by technology. In those fields, knowledge is increasingly produced and circulated in the lingua franca. We know that major multinationals use English as their default language, even when they have been set up in Germany or Finland. The technical discourses thus produced in English circulate among the productive locales in English, reaching the knowledge community wherever it may exist, without need of translation. In that respect, international English would be operating like the international Latin of the medieval period, facilitating numerous exchanges and potentially democratizing the production of knowledge. If you want to do science, you learn English, just as all scholars once had to learn Latin. This is not necessarily a bad thing. Nor, obviously, is it an entirely new phenomenon.

Within those spheres of production, translation tends to play a marginal role. For example, scholars with weak English may seek to have their papers published in that language and will require translation accordingly. Yet even that role is diminishing. The translator working from, say, Catalan into English would now more probably be called upon to revise the Catalan scientist's draft already written in English. To do so is simply more efficient, given that the specialist is more in command of the technical discourse in English than is the generalist translator. Thanks to the same logic, we 
find that the English section of the European Commission's Translation Service is becoming a group of scribes, official rewriters, rather than translators in any strict language-into-language sense.

The picture is quite different if we now consider the linguistic demands operative in the distribution of products. Globalization moves things, trade increases, and innumerable products reach consumers who do not share the language and culture of the producers. Here we find that translation is not only increasing, but that it is changing its key concepts. In the industries most given to marketing in local languages, the reigning concept tends to be "localization" (very loosely seen as translation plus cultural adaptation). More important than the names, however, are a few key changes in discursive production:

- Whereas translation is still thought of in terms of language-into-language situations, where is it meaningful to talk about "source" and "target", globalized distribution operates on the basis of a one-to-many geometry, which is a fundamentally different way of working. We find centralized production of the one "internationalized" text or product, which is basically a source text that has had as many as possible source-culture elements removed. The resulting internationalized version is then more efficiently "localized" (translated and adapted) to a wide range of consumer environments ("locales").

- In the one-to-many scenario, time becomes an essential feature of discursive success conditions. This can be seen in the ideals of the simultaneous shipment of new products, where a translation may be correct but is not operative if it arrives late. It is also a feature of translation services in multilingual bureaucracies.

- The sheer size of most one-to-many communication projects means there is an increase in the hierarchical control and standardization of translation. "Localization" may superficially mean "translation plus adaptation", but these two aspects are increasingly separated. The various translation-memory programs and localization tools restrict the translator's decisions, returning strict translation to the paradigm of phrase-level equivalence, and leaving adaptation to specialists in marketing or engineering.

The basic one-to-many geometry by no means covers all translation situations. It nevertheless successfully accounts for the diversity paradox in ways that translation between source and target cannot. In the fields most subject to globalization, translation into English is significantly different, in its power relations if nothing else, from localization from English. And the terminological shift from "translation" to "localization" maps onto those different directionalities fairly well. This is a major change that Translation Studies has been very late in perceiving. Our discipline is still largely reluctant to convert it into properly theoretical concepts.

The discourse of localization has come from the industry itself, most notably from the fields of software, web-based e-commerce and international information services. Translation Studies has tended not to see those changes, even though the importance of one-to-many geometries was noted quite some time ago (notably in Lambert 1989). This is perhaps because our sights have more traditionally been set on the prestigious international organizations where translation is still thought of in more traditional ways. Entities like the United Nations and the European Union depend on translation for their very functioning, and do so according to a model of ideally symmetrical rights for official languages. In that world, the language-into-language model is still supposed to work, even when the technologies and economies say otherwise. The legal fictions of many protectionist language policies are also extremely convenient for many of the ideologies that circulate in Translation Studies, most notably for the binary models 
we use for the act of translation itself. There are more than 5,000 intergovernmental organizations operative in today's world (see the annual Yearbook of International Organizations); most of them adopt some kind of bilingual or multilingual policy, if only to please the governments they depend on. (Note, though, that there are almost five times as many international non-governmental organizations, whose main preference is for the relative efficiencies of monolingualism.)

This situation suggests that Translation Studies has some kind of intuitive interest in certain models of translation. Perhaps more exactly, Translation Studies has a certain allegiance to situations and organizations in which translation reigns supreme, without subordination to lingua francas, language learning, or tight budgetary constraints on communications. This makes a certain sense, since Translation Studies comprises scholars who choose to study translation rather than economics or general communication. It also makes a kind of intuitive sense when we witness the relative ease with which the cross-cultural ethical ideals of Berman or Venuti, for example, are accepted within the research community as being beyond reproach, and indeed as extending beyond the narrow literary domain. Few feel any need to calculate those ideals in economic terms, to relate them to technological history, or even to question the facile assumptions of source vs. target.

Our purpose here is not to pull apart that political correctness, nor to propose our own. We are instead intrigued by the possibility that, perhaps without knowing it, and despite all our internal divisions, the very idea of Translation Studies presupposes adherence to certain fundamental principles. Those would be the principles that are easily accepted when formulated; they would be the ones considered too evident to challenge. Such principles would surely be the basis for some kind of political identity. They could also constitute a fundamental reason for our general failure to conceptualize the consequences of globalization, particularly the one-to-many geometry and the ways in which the patterns of production and distribution have diverged. Our discipline struggles to perceive the contexts in which its own politics have developed.

\section{The Political}

Let us suppose, for the sake of argument, that there are people who work in the overlaps of cultures. This does not mean these people are somehow without culture, nor that they are in any way universal or a-historical, nor at an ideal mid-point, nor immobile, without allegiances, nor any such pap. There are simply people whose professions require that they know and operate in more than one cultural frame at once. Further, the people we are particularly interested in know and operate on exchanges between cultures. These are the people who move things across language boundaries, who negotiate the fine print of treaties, who produce our transnational news and entertainment, who surround our lives with a million products received in cultures different from the ones they were produced in. Such would be the people of professional intercultures: translators, diplomats, traders, negotiators, technicians manipulating complex codes, when and wherever products and their texts cross cultural boundaries.

Such people exist. You and I might even be among their number, as might our multilingual students. The question here is not just who we are, but what we stand for and how we should act. Those aspects can scarcely be separated. 
What does it mean to act politically? On the face of it, the phrase would involve actions influencing relations between people, particularly the loyalties and alliances that form power and direct its flows. The political pronoun is certainly "we", variously inclusive or exclusive. To act politically, in the intercultural field, might thus mean siding with one culture or the other, or with one aspect of a culture against another, to some degree or another, for one reason or another. I have suggested elsewhere that there are ethical ways of thinking about such acts, without assuming allegiance by birthright or pay-role. It is enough for the intercultural subject to seek long-term cooperation between cultures, or to start reasoning from there (cf. Pym 2000b). Although sweepingly general, this precept is not adequate to all occasions. How, for instance, should it be applied to problems where what is at stake is the identity of Translation Studies, the constitution of a scholarly intercultural "we"?

Where, for example, do "we" stand with respect to globalization? Our research community, perhaps a few hundred people, possibly with several hundred more looking on, is surely too small to seek comparison. Our professional intercultures only loosely resemble those in which production is now specialized; our key productive locations are only in some cases next to centers of capitalist production. Thanks in part to academic distance, we do not particularly follow the orders of either production or distribution. That is certainly one of the reasons why we fail to keep abreast of the way those systems are developing. It is perhaps also why we tend to maintain allegiance to the ideals of former models, believing in translation and national boundaries even when production systems have no great need of either. At the same time, that academic distance might also be why we risk having little of currency to say, or too little power for our voice to be heard.

One can only test those hypotheses on the basis of concrete situations. Here we will briefly consider three cases in which our politics meet globalization.

\section{Empires}

Translation Studies tends to be proportionally strong in the smaller cultures where translation plays a quantitatively significant role (here we are thinking of cases like Belgium, Holland, Israel, Finland, Catalonia, Galicia, Quebec). This is no rule, but it helps explain why our perspectives often concern the defense of minority cultures, the use of general models of cultural alterity (one side facing the other), and a certain intuitive focus on distribution rather than production (cf. the target-side epistemologies of Descriptive Translation Studies and Skopostheorie). A worrying correlative of this is the relative weakness of Translation Studies in the larger monolingual countries where political power tends to accrue, most notably in the United States. We might thus venture that Translation Studies tends to form its intercultures in situations where alterity is already operative as a feature of distribution. That would be where its politics develop. That is also the place from where one looks at production systems, at the centralized intercultures where English reigns, and feigns to find the enemy of translation.

As we have argued, that vision is short-sighted. It confuses the technological with the political. What it tends to see, instead of globalization, is politics of a superpower that has unusually limited awareness of minor cultures, supranational organizations, or virtually any of the things that translation might stand for in our traditional vision. 
In recent years the United States has virtually done away with any pretense to international law. Treaties have been revoked, wars have been initiated on the weakest of excuses, international human-rights conventions are violated on a daily basis, international courts are seen as fine ideas only for as long as no US citizen will be subject to them. Translation is an essential element of the institutions that are thus being flouted. When right is decided unilaterally, without need for consultation or negotiation, or when the consultations and negotiations are simply ignored because they do not reach the right conclusion, then the need for translation is obviated and our object of study will indeed serve little purpose. That scenario is to be resisted. It is not to be mapped onto the inevitabilities of globalization.

To be even blunter: in our small academic political acts, we have before us at least two possible models of contemporary empire. One, in Europe, incorporates translation into its very principles, becoming what one analyst calls the world's first postmodern and potentially cooperative empire (Cooper 2003: 78-79). The other, in the United States, ignores many of the virtues to which translation might hope to contribute, remaining modernist in its insistence on nation. The first kind of empire gains admirable flexibility, defending its borders by extending them, just as its weak inner identity makes it unsuited to any risk-ridden action in the world. The second kind of empire has the unity and force needed for action; it provides international relations with its only real hope of power-based stability; yet it sadly underrates the diversity of human cultures.

What should Translation Studies be doing in such a situation? Within Europe, much work is needed to improve efficiencies and to find ways to combine translation with the use of lingua francas, transcending the jealousies of the nation states. Our key task, however, should be with respect to the more powerful empire, the United States. In that latter context, translation has remained virtually excluded from the agenda of Critical Theory; it is a straggler in the league of Cultural Studies; it is attached as an adjunct to training in interpreting or occasionally as an application of Literary Studies; there is lamentably little connection with anything like the global configuration of cultures; and although all scholars in the humanities have an opinion on translation, very few approach it an as object of study. Sincere praise should be given to the Americans who have fought against this tendency: Marilyn Gaddis Rose, Lawrence Venuti, Douglas Robinson, Edwin Gentzler, Maria Tymoczko, to name a few of the most prominent. Yet they remain isolated voices, in what seems a sea of indifference and incomprehension. They should not, I hope, be isolated as merely American voices. The search for a greater resonance within the institutions of the United States should be a task for our wider identity, not just for the repetition of national divisions.

What is to be done? Publish and speak in the United States, in the discourses fashionable in the United States, no matter where you are from. Extend Translation Studies to the centers of intellectual production.

I work in a small English Department in Spain. My colleagues who work in Literary and Cultural Studies do not consider translation a full-fledged legitimate object of study. They take their operative concepts and agendas from the United States. 


\section{An association}

Perhaps the clearest sign of our décalage with respect to globalization is the extent to which Translation Studies remains organized along national lines. Our academic discipline has generally ridden on the back of translator-training institutions, either directly or indirectly, and those institutions mostly operate within national education systems. Even beyond the concerns of translator training, however, the political organization of Translation Studies has largely been oriented along national lines. The Canadian Association of Translation Studies might be an example of this, as could similar associations in the United States, Brazil and Japan (for interpreting). There are also associations that run across national boundaries, such as the European Society for Translation Studies and the Iberian association that brings together Spain and Portugal. But why should all these associations have remained geopolitically national or regional?

One could argue that the problems of translation are fundamentally different in different geopolitical contexts. The official bilingualism of Canada creates a highly specific field that wholly justifies a certain approach to translation, along with a certain restriction to French and English. In Europe, the future of translation is undoubtedly marked by the language practices (there is no communication policy) of the European Union, which creates a series of quite different problems. The justification for the Iberian association is a little harder to fathom, although it might legitimately spring from a sense of being excluded by other European discourses on translation. The education systems are still organized along national lines; national governments still have language and communication policies that we might be able to inform; there are still national and regional subsidies to apply for. There is thus still a level at which certain translation problems, particularly with respect to professional status, require a nationally based approach. If one looks hard enough, one can find reasons for a certain political organization at quite small geo-political levels. Indeed, I would personally like to see more work along local lines, with what anthropologists call local knowledge, and a little less adulation of the international stars of Translation Studies. The prime reason for this is the general failure of Translation Studies, more than 30 years after James S. Holmes (1972) coined the name and mapped the discipline, has produced almost no intellectual product of direct benefit to the translation profession on any international level. The most significant contribution to the profession has perhaps been the development of translation memory software, and that has not happened within Translation Studies. On the other hand, our waves of theorizing and the building up of a body of empirical knowledge can and has been of direct use in translator training. But the transfer of that knowledge has been far from international. Indeed there was long a problematic lack of enlightened international textbooks and journals accessible to the teaching institutions. The transfer of knowledge from research to teaching has very largely been at the national or regional level, with significant differences often ensuing from the nature of the education systems involved. For that reason, the development of Translation Studies at national levels might even be considered appropriate to the specificities of at least that part of the discipline's tasks.

On the other hand, despite the imperatives of transfer, the actual studies we produce tend to reflect remarkably little geopolitical bias. As the initial language 
differences are reduced (for example, the initial development of Skopostheorie in German), publications like Meta, TTR, or Target are nowadays different not because of where they are printed but because of the academic preferences of individual editors and their committees. Some journals want to be closer to practice, others more empirical, and still others cherish the legacy of linguistics. The same authors tend to appear in all; much the same methodologies are used, regardless of the regional context. No matter how much the actual problems of translation might depend on national contexts, no matter how much the demands for transfer are local, the research problems of Translation Studies would seem to be rather more global.

This is as it should be. As professional associations, we tend to come together not because we are similar in any iconic or legalistic way (with regard to race, language, citizenship or whatever) but precisely because we are of diverse provenance, each bringing different expertise and experience with regard to languages, cultures and research methodologies. That is what intercultures are all about. We need those differences not just because of our declared status as an interdiscipline but more especially by virtue of the nature of translation itself, which assumes knowledge of a cultural other. As an academic discipline, we are given to straddling cultural borders, engaging our dialogues beyond the national, constructing our own particular forms of interculturality. Further, thanks to our academic non-conformity with globalization, those general principles have no reason to be restricted to the centers of production. Our intercultures could and should embrace interested scholars from all cultures, no matter how small or far-flung, or rather, particularly from those that work in minority situations and struggle against geophysical distance. For those reasons, our professional associations should be operating at a global level, in addition to the work they do at the national and regional levels.

There is no excuse for the long absence of a truly international association of Translation Studies. We should thus welcome the creation of the International Association of Translation and Intercultural Studies (IATIS) in 2004. This should have been achieved by federating the existing national and regional associations, thus creating some kind of global unity. As it happened, the international association was an independent start-up, created in order to integrate the many peripheral situations apparently excluded by the previously existing associations. That is a noble and necessary aim. In this, again, we see the propensity of Translation Studies to defend the local, the particular, the minor, even from the perspective of its most willfully globalized association.

\section{A boycott}

Here is another political act that worries me. I am asked to sign a petition calling for the boycott of "research and cultural" links with citizens of a particular country. That country has acted illegally, inhumanely, atrociously, as far as I can tell. So too has the country I was born in. Even worse is the colonial record of the country whose passport I now carry. The petition asks me to identify researchers and artists with the state they work within. To act politically would be to make this identification, in the hope they will then pressure that state from within, or something like that. Unfortunately, not signing the petition is denied status as a political act; no one has invited me to sign a document expressing solidarity with all those who condemn their state's actions. This 
one-sidedness is the first reason for considering the act a problem. How many alternatives does the political act give us?

Here is yet another political act that worries me. The editor of the journal The Translator dismissed members from the editorial board because of the country their universities are in, using the same general reasoning as above. In this case, though, the one-sidedness is not as much a problem, since there has been much discussion of the act within Translation Studies.

Here we see that the national principle can be used not only to organize Translation Studies, as has so far been the case in our organizations, but also to exclude some translation scholars. That is nationalism in reverse. It runs counter to the interests of Translation Studies on almost every level imaginable. It divides the international research community; it does so with respect to issues that do not concern translation; it cannot lead to any increased cooperation between cultures.

Such historical tests are nevertheless instructive. They sometimes allow us to discover the principles that we did not know we had. The almost general rejection of the nationalist exclusion should be seen as a reaction not just against something that is felt to be wrong, but as an affirmation of what is instinctively right: the international community of scholars working together to solve the problems of their field. Thus might we discover that our professional relations are more important than our passports or personal opinions about foreign states. We could find that the interdiscipline requires dialogue across real difference, rather than the imposition of political certitude. In short, we might discover our status as a particular kind of professional interculture, as a community that operates beyond the primary allegiances of birthright, employment, or party politics.

To be sure, awareness of those fundamental principles has been obscured by the inept way in which this debate was initiated, with arguments fit more for the glassyeyed convictions of an English pub. The issue, for me, was long clouded by barrages of insulting email from various pressure groups, demonstrating the power of manipulated opinion. It has more recently been complicated by occasional insults being thrown at the intellectual community for its failure to support the boycott. The disparaging tone of those asides indicates not only real and justified despair, but a severe misunderstanding of how an intercultural community of scholars works. In the western tradition, our interculturality dates at least from the traveling intellectuals of the twelfth century, when study already required a year abroad, and Latin enabled communication between ideas of very different provenance. That tradition borrowed from the Islamic system of colleges, dating from the eighth century; it has consistently survived attempts to locate intellectuals at national courts or to have universities work exclusively for nation states. Our academic distance has been very hard-won in political terms. Our institutions are considerably older and wider than most nation states. They will certainly outlive the outrageous injustices of our day. They are not easily dismissed. Their own particular interculturality is worth preserving.

That kind of intellectual community carries the weight of history. Thanks to its principles, there can be no excuse for the collective exclusion of scholars simply by virtue of their national affiliation.

Our own globalization requires at least that ethical stance. There is a final irony, however. Those who would apply an exclusive nationalism are now, in a classical fuite en avant, at the forefront of the International Association of Translation and 
Intercultural Studies. For that reason, I am unable to participate in that association. At this point, among others, globalization requires strong decisions.

To work on translation involves engaging with principles about relations between cultures, about certain aspects of globalization that allow for decisions, and thus about our own cultural configuration as a research community. Those principles must be discovered, evaluated, modified, or defended, as part of an on-going process of collective reflection. And our day-to-day political practice is the way this is done.

\section{REFERENCES}

Boucau, F. (2005): “The European Translation Industry: Facing the Future," Brussels, European Union of Associations of Translation Companies.

Cooper, R. (2003): The Breaking of Nations. Order and Chaos in the Twenty-First Century, London, Atlantic.

Holmes, J. S. (1972): “The Name and Nature of Translation Studies," expanded version in Translated! Papers on Literary Translation and Translation Studies, Amsterdam, Rodopi, p. 6680.

LAMBERT, J. (1989): «La traduction, les langues et la communication de masse. Les ambiguités du discours international», Target 1-2, p. 215-237.

Рум, A. (2000a): Negotiating the Frontier: Translators and Intercultures in Hispanic History, Manchester, St Jerome Publishing.

Рум, A. (2000b): “On Cooperation," Intercultural Faultlines: Research Models in Translation Studies I: Textual and Cognitive Aspects, Maeve Olohan (ed.) Manchester, St-Jerome Publishing, p. 181-192.

Ricardo, D. (1821): On the Principles of Political Economy and Taxation, third edition (first published 1817), London, John Murray.

Venuti, L. (1995): The Translator's Invisibility. A History of Translation, London and New York, Routledge.

Venuti, L. (1998): The Scandals of Translation, London and New York, Routledge. 